\title{
A RARE CASE OF PRIMARY EMPTY SELLA SYNDROME AND GROWTH HORMONE EXCESS IN A PATIENT WITH NEUROFIBROMATOSIS TYPE 1
}

Elena Iuliana Paşcu ${ }^{1}$, Mihaela Epure ${ }^{1}$, Amalia loana Arhire ${ }^{1}$, Sorina Martin ${ }^{1,2}$, Simona Fica $^{1,2}$
${ }^{1}$ Elias Emergency Hospital, Endocrinology Department, Bucharest, Romania
${ }^{2}$ Carol Davila University of Medicine and Pharmacy, Endocrinology Department, Bucharest, Romania

\section{INTRODUCTION}

Neurofibromatosis type 1 (NF1) is the most common type of NF, and accounts for about $90 \%$ of all cases. Primary empty sella syndrome (ESS) results from herniation of arachnoid mater into the pituitary fossa. Since it has been demonstrated that the small anterior pituitary size reflects loss of neurofibromin expression in the hypothalamus, leading to reduced growth hormone releasing hormone (GHRH), pituitary growth hormone (GH) and liver insulin-like growth factor-1 (IGF1) production, we agree that IGF1 and GH increased in our patient can be challenging.

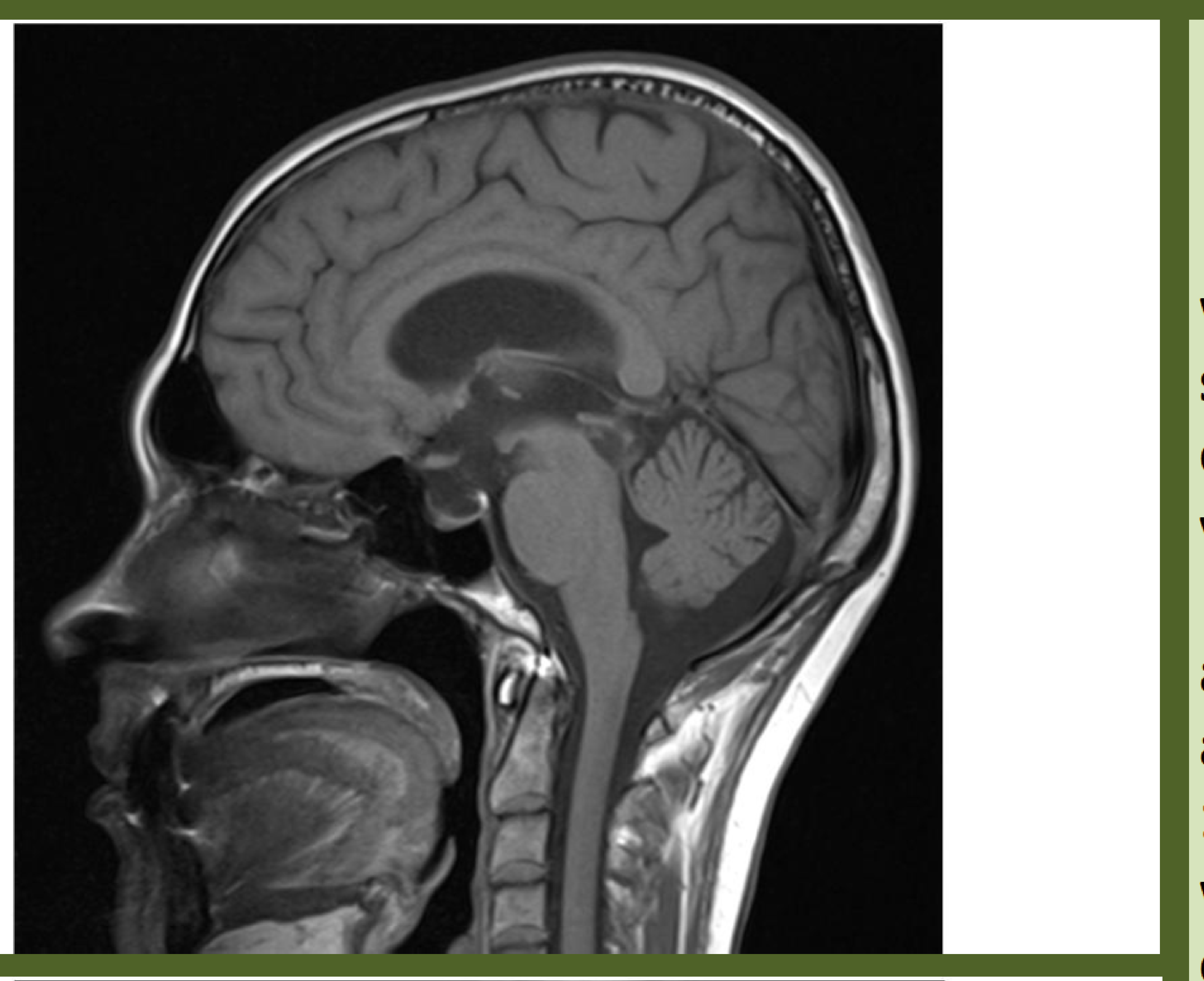

\section{CASE REPORT}

We report the case of a 33-year-old woman, diagnosed at birth with NF1, with a single spontaneous menstrual cycle at 14 years, secondary amenorrhea and estroprogestative substitution treatment ever since, diagnosed with primary ESS, hydrocephaly and central ventricular system malformation at 18 years.

Physical examination revealed 6 café au lait macules on the trunk and neck region, multiple plexiform neurofibromas in the cervical area, supraclavicular fossa and upper thorax. Blood pressure was $115 / 100 \mathrm{mmHg}$, without orthostatic hypotension. The fluid intake was normal. She had no hystory of head trauma, pregnancy or childbirth.

Lab tests : IGF1 $=413 \mathrm{ng} / \mathrm{ml}(115-307 \mathrm{ng} / \mathrm{ml})$, ACTH=12.6 pg/ml, $\mathrm{TSH}=0.893 \mu \mathrm{lU} / \mathrm{ml}, \mathrm{FT} 4=0.851 \mathrm{ng} / \mathrm{dl}, \mathrm{TPOAb}<10 \mathrm{UI} / \mathrm{ml} \quad(\mathrm{N}<35)$, PTH $=46.5 \mathrm{pg} / \mathrm{ml}, 8 \mathrm{am}$ serum cortisol=12.9 $\mu \mathrm{g} / \mathrm{dl}$, plasmatic metanephrines $=15.1 \mathrm{pg} / \mathrm{ml}(\mathrm{N}<90)$, plasmatic normetanephrines $=35.8 \mathrm{pg} / \mathrm{ml} \quad(\mathrm{N}<180)$. Oral glucose tolerance test showed unsuppressed GH on glucose load (nadir $\mathrm{GH}=1.710 \mathrm{ng} / \mathrm{ml}$ ).

Thyroid, breast, abdominal and pelvic ultrasound were normal. Bone densitometry: Z-score spine $=\mathbf{- 2 . 5}$ SD. Pituitary MRI : empty sella without pituitary adenoma.

We consider that $\mathrm{GH}$ hipersecretion could be due to ectopic secretion of $\mathrm{GH} / \mathrm{GHRH}$ requiring further evaluation.

\section{CONCLUSIONS}

ESS is a rather frequent neuroradiological finding in the general population and can be associated with hypopituitarism. It is clear that GH deficiency is more common in patients with NF.

Since this rare case presents a young patient with NF, ESS and an uncommon excess of $\mathrm{GH}$, careful imagistic evaluation, diagnosis and follow-up appears to be essential in the management of NF1 patients.

\section{REFERENCES}

- Parichehr Ghalavani, Zahra Saheri and Farimah Sardari, Neurofibromatosis type I (von Recklinghausen's disease): A family case report and literature review Dent Res J (Isfahan). 2012 Jul-Aug; 9(4): 483-488.

-Balasz Hegedus, Tu-Hsueh Yeh, Da Yong Lee, Ryan J. Emnett, Jia Li, and David H. Gutmann, Neurofibromin regulates somatic growth through the hypothalamic-pituitary axis. Hum Mol Genet. 